\title{
The influence of large amplitude planetary waves on the Antarctic ozone hole of austral spring 2017
}

\author{
Oleksandr Evtushevsky ${ }^{\mathrm{A}, \mathrm{E}}$, Andrew R. Klekociuk ${ }^{\mathrm{B}, \mathrm{C}}$, Volodymyr Kravchenko ${ }^{\mathrm{A}}$, \\ Gennadi Milinevsky ${ }^{\mathrm{A}, \mathrm{D}}$ and Asen Grytsai ${ }^{\mathrm{A}}$ \\ A Astronomy and Space Physics Department, Faculty of Physics of Taras Shevchenko National \\ University of Kyiv, 64/13, Volodymyrska Street, City of Kyiv, Ukraine, 01601. \\ ${ }^{B}$ Australian Antarctic Division, Kingston, Tas., Australia. \\ ${ }^{\mathrm{C}}$ Antarctic Climate and Ecosystems Cooperative Research Centre, Hobart, Tas., Australia. \\ ${ }^{D}$ College of Physics, International Centre of Future Science, Jilin University, Changchun, China. \\ ECorresponding author. Email: o_evtush@ukr.net
}

\begin{abstract}
Quasi-stationary planetary wave activity in the lower Antarctic stratosphere in the late austral winter was an important contributor to the preconditioning of the ozone hole in spring 2017. Observations show that the ozone hole area (OHA) in spring 2017 was at the level of 1980s, that is, almost half the maximum size in 2000s. The observed OHA was close to that forecasted based on a least-squares linear regression between wave amplitude in August and OHA in September-November. We show that the key factor which contributed to the preconditioning of the Antarctic stratosphere for a relatively small ozone hole in the spring of 2017 was the development of large-amplitude stratospheric planetary waves of zonal wave numbers 1 and 2 in late winter. The waves likely originated from tropospheric wave trains and promoted the development of strong mid-latitude anticyclones in the lower stratosphere which interacted with the stratospheric polar vortex and strongly eroded the vortex in August and September, mitigating the overall level of ozone loss.
\end{abstract}

Received 14 February 2018, accepted 1 July 2019, published online 11 June 2020

\section{Introduction}

Interannual variability in the ozone hole size and depth is strongly influenced by planetary wave activity (Shindell et al. 1997; Allen et al. 2003; Huck et al. 2005; Salby et al. 2012). The flux of wave energy propagating from the troposphere into the stratosphere influences the strength and temperature of the stratospheric polar vortex, where the ozone hole forms in the austral spring. Increased wave activity destabilises the polar vortex during the winter and spring months, reduces total duration of the ozone hole and decreases ozone loss. The southern hemisphere $(\mathrm{SH})$ polar stratosphere can be disturbed by the planetary waves generated in the tropics, as well as in the mid- and polar latitudes (Kodera and Yamazaki 1989; Nishii and Nakamura 2004; Huck et al. 2005; Peters et al. 2007; Grassi et al. 2008; Agosta and Canziani 2011).

Many indicators are used to forecast the seasonal evolution of the ozone hole, and the main of them is wave forcing from the troposphere (Shindell et al. 1997; Salby et al. 2012). The results of Shindell et al. (1997) have demonstrated that midwinter tropospheric wave energy may be the best predictor of the severity of the ozone hole the following spring. By Salby et al. (2012), if the planetary wave structure at tropospheric levels and upward wave flux into the stratosphere are known during late winter, then the observed dependence determines the subsequent depletion of ozone during spring.
Following Grytsai et al. (2008) and Kravchenko et al. (2012), we use the quasi-stationary wave (QSW) amplitude in air temperature of the lower Antarctic stratosphere in August (late austral winter) to investigate the development of the ozone hole in spring 2017. The QSW activity in the SH stratosphere is an important component of the planetary waves penetrated from the troposphere. As shown by Grytsai et al. (2008), large anomalies in the lower stratospheric QSWs between 50 and $80^{\circ} \mathrm{S}$ in August favoured the development of an anomalously small ozone hole in the springs of 1988 and 2002 (their figure 6). Interannual variations in the QSW amplitude (QSWA) in August show maximum correlation with Antarctic ozone in August-November of up to $r \sim 0.8$ (Kravchenko et al. 2012, their figure 4).

These results are evidence that QSW activity in the Antarctic stratosphere in late winter regulates, to a certain extent, the overall size of the ozone hole in spring. In this work, we analyse the role of large amplitude QSW, as well as travelling planetary waves of zonal wave numbers 1 and 2, in August 2017 in preconditioning of the ozone hole. We also pay attention to the stratospheric anticyclones and related tropospheric wave patterns.

\section{Data}

The monthly mean QSWA in air temperature between 50 and $80^{\circ} \mathrm{S}$ at $50 \mathrm{hPa}$ (T50) in August was obtained from 

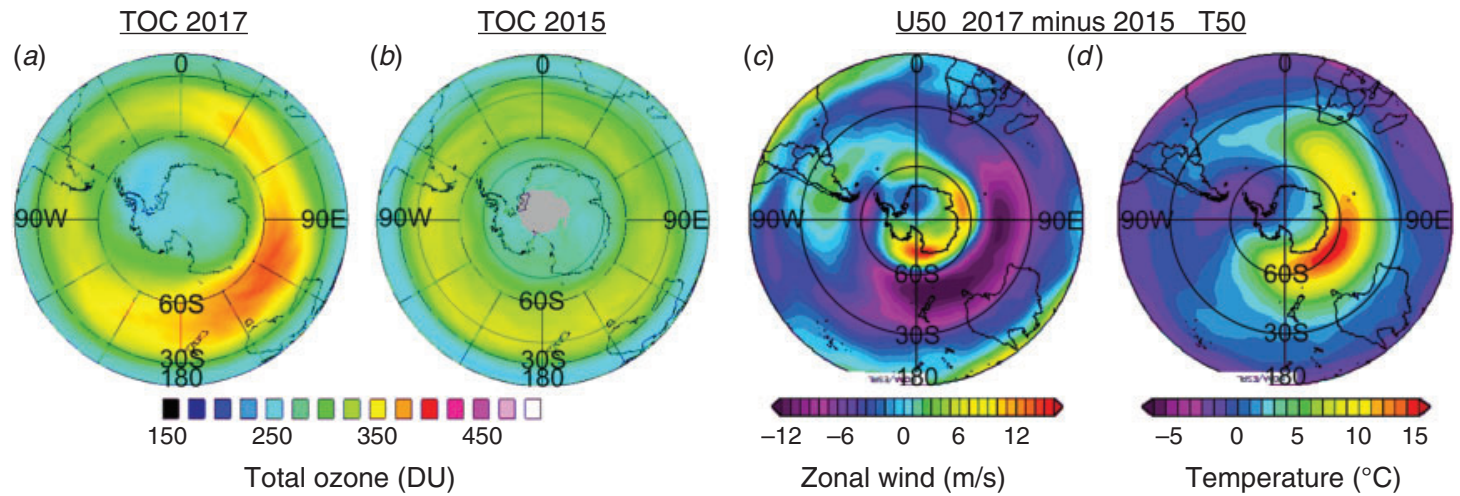

Fig. 1. Stratospheric anomalies in August 2017 compared to August 2015: $(a, b)$ total ozone from Ozone Monitoring Instrument observations, $(c)$ and $(d)$ differences between August 2017 and August 2015 in zonal wind and air temperature respectively at $50 \mathrm{hPa}$ from NCEP-NCAR reanalysis.

NCEP-NCAR reanalysis (NNR) data at https://www.esrl.noaa. gov/psd/cgi-bin/data/getpage.pl, accessed 30 April 2020. We follow the approach used by Kravchenko et al. (2012) where the QSWA is defined as one half of the difference between the peak maximum and minimum temperature for the particular latitude and pressure. A time series for 1979-2017 was created and linearly detrended to represent the QSWA anomalies. Geopotential height $Z$ and zonal wind $U$ data are also used from the NNR website. Stratospheric air trajectories are compared to $Z$ and $U$ fields using wind maps from the Global Forecast System (GFS) NCEP/US National Weather Service at https://earth. nullschool.net/, accessed 30 April 2020.

The ozone data were used from the three sources. The ozone hole area (OHA) was averaged for October and SeptemberNovember using daily values from the Ozone Hole Watch website at https://ozonewatch.gsfc.nasa.gov/meteorology/SH. $\mathrm{html}$, accessed 30 April 2020. Maximum ozone depletion is usually observed in October, and we analyse the OHA sensitivity to the dynamical preconditioning in the late winter. The OHA time series for 1979-2017 was detrended using a third-order polynomial to remove the non-linear decadal trend.

The total ozone fields derived from the ozone monitoring instrument (OMI) observations are available at https://www. temis.nl/protocols/O3global.html, accessed 30 April 2020. The individual layer ozone data at the middle stratosphere level are based on the Aura/Microwave Limb Sounder ozone data at https://mls.jpl.nasa.gov/, accessed 30 April 2020.

Detrended time series were linearly correlated and linearly regressed. In order to estimate possible prediction uncertainty, the standard linear regression was compared with the reduced major axis regression and weighted linear regression (e.g. Wu and $\mathrm{Yu}$ 2018). Statistical significances of the correlations and regressions were estimated using the Student $t$-test.

\section{Results}

\subsection{Zonal asymmetry}

Signs of anomalous evolution of the ozone hole in spring 2017 were observed during the winter months (Klekociuk et al. 2019), and we illustrate the late-winter anomalies in total ozone column
(TOC), zonal wind and temperature at $50 \mathrm{hPa}$ (U50 and T50 respectively) in Fig. 1. The August conditions in 2017 are compared to those in 2015 , the year of an anomalously strong and persistent ozone hole (Klekociuk et al. 2019).

In August 2017, zonally asymmetric TOC anomaly in midlatitudes of the Australian sector $\left(90-180^{\circ} \mathrm{E}\right)$ was apparent (Fig. 1a) that indicated increased planetary wave activity. The TOC field in August 2015 was quite concentric relative to the South Pole with much lower TOC maximum, as it is typical for the conditions of low wave activity and strong stratospheric polar vortex. Differences 'August 2017 minus August 2015' show that zonal wind U50 in 2017 in the Australian sector was weaker than in 2015 by $10-12 \mathrm{~m} / \mathrm{s}$ (Fig. 1c). This would be expected to promote more wave energy to penetrate into the stratosphere (following Charney and Drazin 1961), further weakening the polar vortex, heating the stratosphere and, thus, preconditioning the stratosphere for reduced ozone depletion in spring. Related warming of the lower stratosphere in the same zonally asymmetric region is seen in Fig. 1d. Clear zonal symmetry in TOC, U50 and T50 (Fig. 1) demonstrates the dominance of the QSW with zonal wave number 1 (QSW1).

\subsection{Statistical relationships}

The largest anomalies in the August QSWA in T50 between 50 and $80^{\circ} \mathrm{S}$ were observed in 1988, 2002 and 2017 (blue, black and red curves respectively in Fig. $2 a$ ). It is seen from Fig. $2 a$ that the highest QSWAs in these years are at the high southern latitudes $60-70^{\circ} \mathrm{S}$. From the simple least-squares linear regression for the 1979-2016 period (Model 1, dashed line in Fig. 2b), the QSWA anomaly in August indicated that the OHA in October 2017 would be at the level of October 2012, but the observed value was somewhat larger (dashed and solid open circles respectively in Fig. $2 b$ ).

We have examined the reduced major axis (or orthogonal distance) regression method (Wu and $\mathrm{Yu}$ 2018) using the same time series (Model 2, dotted line in Fig. 2b). The regression line slope in Model 2 is steeper than in Model 1 (dotted and dashed lines in Fig. $2 b$ respectively; compare also the regression coefficients $b_{1}$ and $b_{2}$ at the top of Fig. 2b). Additionally, the 

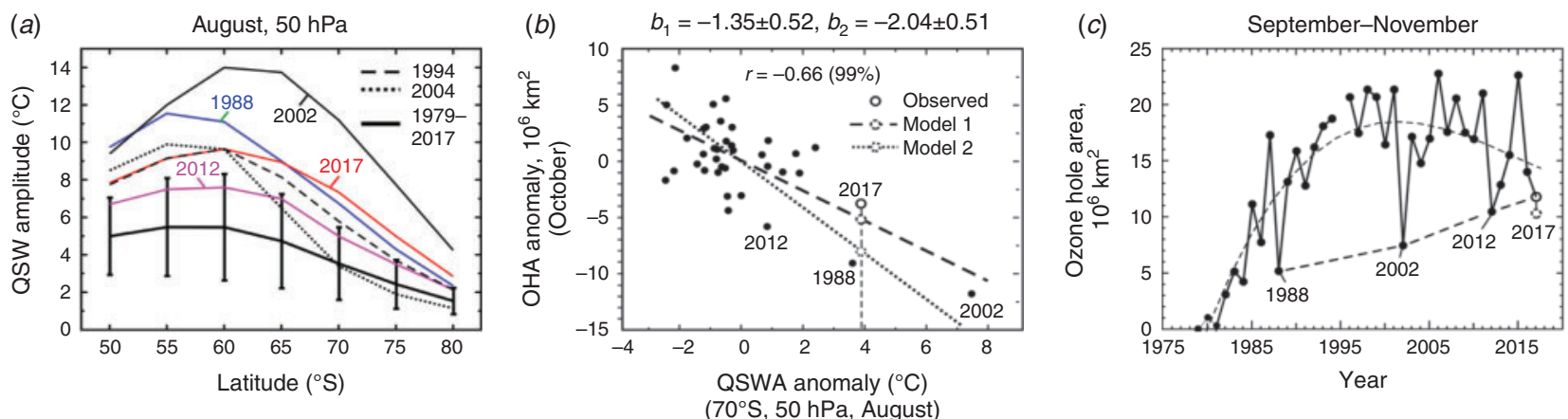

Fig. 2. (a) Meridional profiles of the quasi-stationary wave amplitude (QSWA) in T50 in August at seven latitude circles between 50 and $80^{\circ} \mathrm{S}$ for the anomalous year (thin curves) compared to climatology 1979-2017 (thick curve with the standard deviation vertical bars). (b) Regression of the QSWA anomalies at $70^{\circ} \mathrm{S}, 50 \mathrm{hPa}$ in August to the ozone hole area (OHA) anomalies in October; solid (dashed and dotted) open circles indicate observed (predicted by regression: Models 1 and 2 respectively) OHA anomaly in October 2017. (c) Time series of the OHA averaged over September-November 1979-2017; solid (dashed) open circle as in (b), but for OHA in September-November 2017; note the gap in the OHA data in 1993.

predicted OHA anomaly in Model 2 is closer to the level of 1988 (dotted open circle in Fig. 2b), that is, further removed from the observed value than for Model 1. This may suggest that the use of Model 1 is a more appropriate method for this particular type of analysis. Linear regression based on time series of standardised anomalies OHA and QSWA and weighted regression based on the weighted OHA values (the linear regression techniques are described in more detail in $\mathrm{Wu}$ and $\mathrm{Yu}$ 2018) show even smaller difference between observed and predicted OHA in 2017 (not shown).

The correlation coefficient between the OHA and QSWA anomalies in Fig. $2 b$ is $r=-0.66$ (significant at the 99\% confidence limit). This means that $\sim 44 \%$ of the OHA variance is explained by the QSWA variance and thus the contribution from the large QSWA events in August appears important. However, the remaining 56\% of the OHA variance in October evidently depends on other dynamical and chemical factors. Note the much smaller presence of the large-amplitude QSW anomalies in the SH than in the northern hemisphere due to weaker wave driving (Hardiman et al. 2010). The OHA and QSWA anomalies in 1988 and 2002 are the only ones that reached the $2 \sigma$ level or above (not shown). Such events contribute to more accurate quantitative description of the 'QSWAOHA' dependence in a range of the large anomalies, although the difference between the prediction of the 2017 OHA and that observed depends on the regression model used (Fig. 2b). In the case of the OHA statistics averaged over the three spring months September-November, Model 1 gives a difference between predicted and observed values that is similar to that for October (dashed open circles in Fig. $2 c, b$ respectively). Overall, the similarity between the observed OHA values and those predicted by linear regression provides further evidence that strong late-winter QSW activity has an important preconditioning influence on the ozone hole during the subsequent spring (Grytsai et al. 2008; Kravchenko et al. 2012).

Note that QSW1 and QSW2 occasionally exhibited increased activity in the course of winter and spring, JuneNovember, 2017 (Klekociuk et al. 2019) which weakened and heated the polar vortex and decreased the overall severity of the ozone hole.

\subsection{Large amplitude planetary waves in August 2017}

As shown in Klekociuk et al. (2019), variable daily amplitudes of waves 1 and 2 were observed in the lower stratosphere from June to November 2017 (their figure 9). The effect of enhanced wave 1 in total ozone is shown by the OMI data for $12-14$ August 2017 (Fig. 3). It should be emphasised that the TOC maximum appears around $90^{\circ} \mathrm{E}$ and shifted eastwards to $180^{\circ} \mathrm{E}$ passing the Australian sector, where the climatological QSW maximum exists. This event undoubtedly contributed to the large mean QSWA in August 2017 (Figs 1a, 2a).

Although less important for the total ozone variations, nonetheless interesting in terms of stratospheric dynamics is the ozone filament that stretched between the tropics and the polar vortex edge (arrows in Fig. 4). The upper panel in Fig. 4 shows that, in the layer $26-10 \mathrm{hPa}$, filament appears over South America on 19 August and elongated polewards and eastwards on 20-21 August following the wave 2 maximum, which shifted over the Atlantic sector and south of Africa around $0^{\circ} \mathrm{E}$ (arrows in Fig. $4 a-c$ ). Approaching the vortex edge, the filament contributed to an increase in the wave 2 maximum in total column ozone near the Greenwich meridian (Fig. $4 e, f$ ).

A detailed view of the wave 2 development on 19-21 August 2017 is shown in Fig. 4. As seen from the OMI TOC fields in Fig. $4 d-f$, wave 2 zonal maxima intensified and shifted eastwards during the 3 days as was also the case of wave 1 in Fig. 3 . The strongest wave 2 ridge redeveloped mainly in the Australian sector and this additionally contributed to the large amplitude QSW in the monthly mean values for August 2017 (Figs 1a, 2a).

Similar planetary-scale 'tongues' of tropical stratospheric air extending out from the tropics into the mid-latitudes of the southern and northern hemispheres have been described by Randel et al. (1993) and Waugh (1993). In the SH, they are fixed geographically in the same region as in Fig. 4 (see the discussion in Section 4). 
OMI total ozone 12-14 August 2017
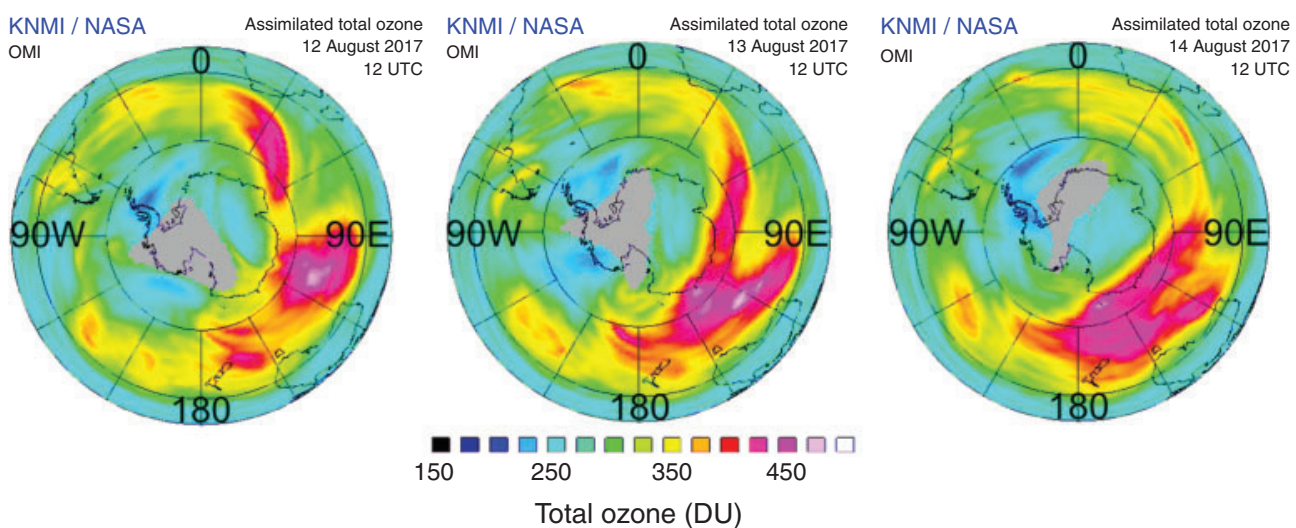

Fig. 3. Wave 1 event represented by the distribution of the Ozone Monitoring Instrument (OMI) total ozone over the southern hemisphere during 12-14 August 2017.

\section{Aura/MLS ozone $26-10 \mathrm{hPa}$}
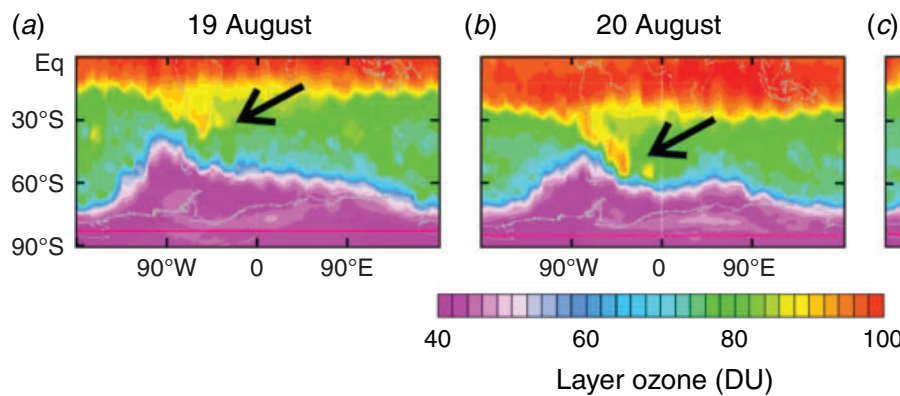

(c) 21 August

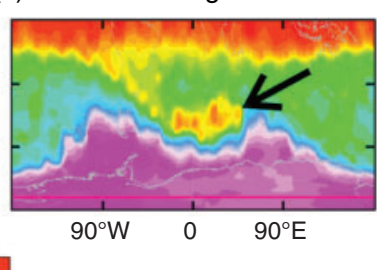

OMI total ozone

(d)

(e)

20 August

(f) 21 August
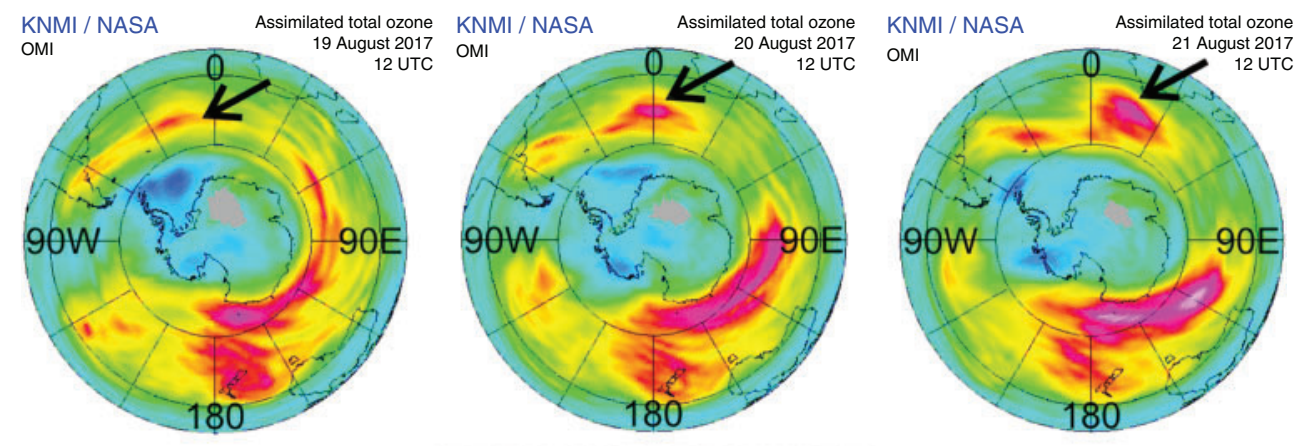

150

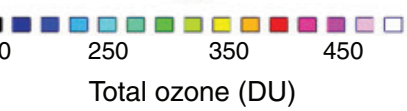

Fig. 4. Wave 2 event in the SH stratosphere during 19-21 August 2017: $(a-c)$ partial stratospheric ozone column in the layer between 26 and $10 \mathrm{hPa}$ from Aura/MLS data; $(d-f)$ total ozone column from Ozone Monitoring Instrument (OMI) data.

We present some evidence that appearance of wave 1 or 2 in the SH stratosphere in August 2017 was associated with the structure and prevailing location of the tropospheric wave train that determined the vertical propagation of the wave disturbances.
The left column of Fig. 5 illustrates the formation of a wave 1 pattern in the lower middle stratosphere on 12 August 2017 (Fig. 3). The Z500 anomalies show the existence of a strong wave train over Atlantic and Indian oceans. As planetary wave 
12 August 2017
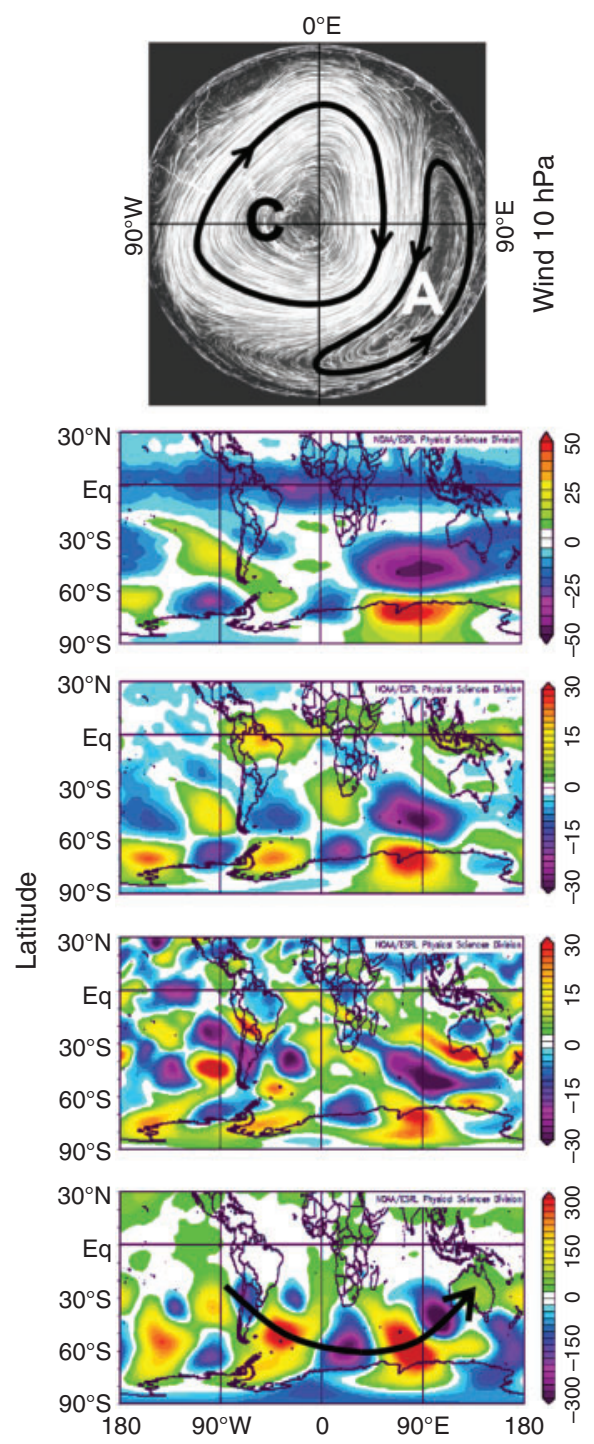

21 August 2017
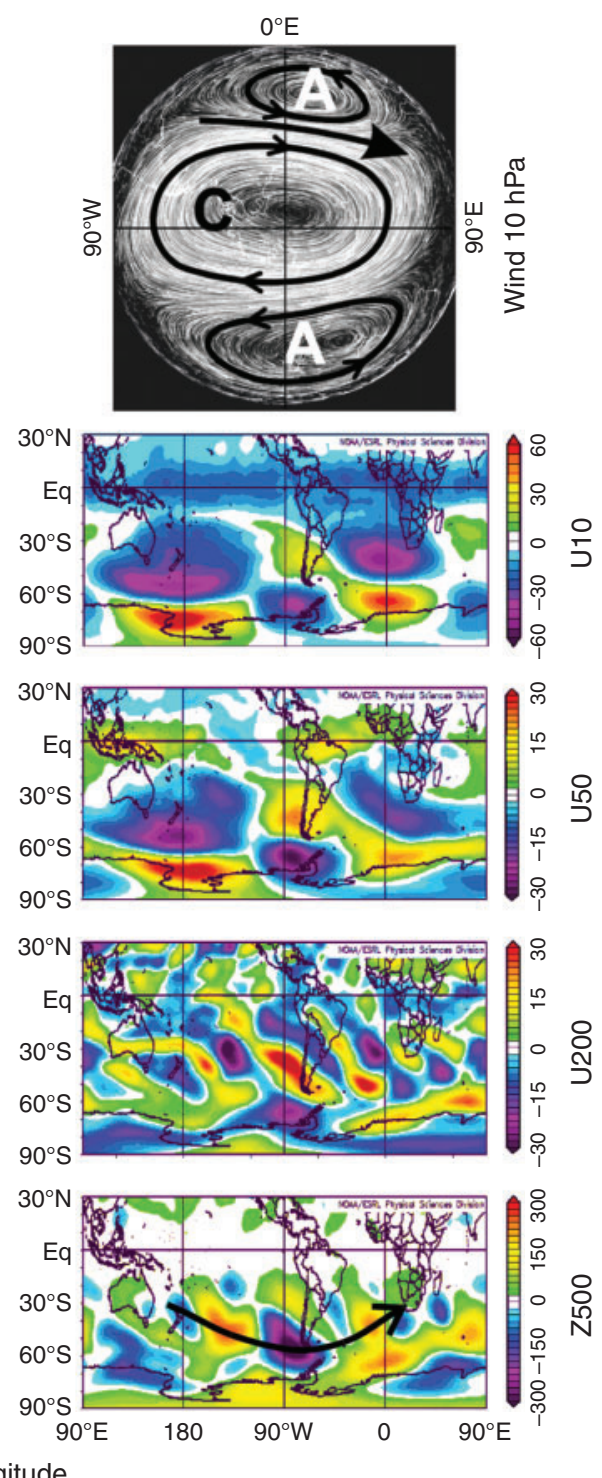

Fig. 5. (Left) Wave 1 and (right) wave 2 events in the SH atmosphere in August 2017. Geopotential height anomalies at $500 \mathrm{hPa}$ (panel Z500, in $\mathrm{m}$ ) and zonal wind anomalies at 200, 50 and $10 \mathrm{hPa}$ (panels U200, U50 and U10 respectively, in $\mathrm{m} / \mathrm{s}$ ) relative to the NNR climatology 1981-2010 and wind fields at $10 \mathrm{hPa}$ (upper panel) from GFS/NCEP/US National Weather Service are presented. Arrowed contours show circulation directions, and the long arrow on the upper right plot indicates the location and propagation of the filament shown in Fig. $4 a-c$. Note that the longitude axes on $U$ and $Z$ maps are centred at (left) $0^{\circ} \mathrm{E}$ and (right) $90^{\circ} \mathrm{W}$. GFS, Global Forecast System; NNR, NCEP-NCAR reanalysis.

trains are usually propagated eastwards (arrow on the left plot $\mathrm{Z500}$ ), the source region of the wave train was potentially located in the tropical Pacific.

Upward propagation of the wave disturbances resulted in only a single zonal anomaly reaching the middle stratosphere in both high and middle SH latitudes (left plot sequence U200, U50 and U10). This vertical transformation of the wave pattern displays the tendency of the longest wave to penetrate from the troposphere to the stratosphere (Charney and Drazin 1961). Positive and negative zonal anomalies in U10 at the high- and middle latitudes mean eastward and westward rotation, respectively, of stratospheric air in cyclonic and anticyclonic circulation. This is confirmed by the wind field structure at $10 \mathrm{hPa}$ on the upper left plot in Fig. 5: anticyclone A was located in the Australian sector equatorward of the polar cyclone $\mathrm{C}$ (arrowed contours).

The right column of Fig. 5 demonstrates the appearance of a wave 2 pattern in the stratosphere on 21 August 2017 (Fig. 4). In this case, the planetary wave train was located in the troposphere 
of the Pacific and Atlantic basins (arrow on right plot Z500). Such tropospheric wave forcing produced two zonal anomalies in the middle stratosphere as a result of vertical wave propagation (right plots U200, U50 and U10). As can be seen in the upper right plot of Fig. 5, zonal wind anomalies on 21 August 2017 cause a formation of the two stratospheric anticyclones (marked ' $\mathrm{A}$ ') around 0 and $180^{\circ} \mathrm{E}$. Note that the filament between the tropics and polar vortex (Fig. $4 a-c$ ) was drawn in between the cyclonic polar vortex itself (marked ' $\mathrm{C}$ ') and anticyclone $\mathrm{A}$ near $0^{\circ} \mathrm{E}$ (long arrow on upper right plot).

It should be noted that zonal wave 3 patterns in the Z500 anomalies were also present with the wave ridges over the oceans, which are more clearly visible on the plot for 12 August. Similar wave patterns are reproduced in the sea-level pressure anomalies (not shown) that indicate the appearance of the anticyclonic anomalies in the mid-latitude ocean basins. The sea-surface temperature anomalies (not shown) were strongest in the subtropics (12 August) and western (positive) and eastern (negative) tropical Pacific (21 August), and a more thorough analysis of the wave train origins and sources is necessary.

To what extent the tropospheric wave train patterns and location played a role in the stratospheric anticyclone formation in wave 1 and wave 2 events in August 2017 and what surface anomalies caused the wave train differences also need to be explained in further studies. Nevertheless, the results of Figs 2 and 5 support the dependence of the ozone hole in spring on both the intensity of the planetary wave forcing and the wave structure in the troposphere in late winter that affords a seasonal forecast of springtime ozone depletion (Salby et al. 2012).

\section{Discussion}

We have analysed the role of large-amplitude quasi-stationary planetary waves in preconditioning the ozone hole in austral spring 2017. We focus on the late-winter month August in order to examine the preconditioning QSW potential for this month suggested by Grytsai et al. (2008) and Kravchenko et al. (2012). The QSW activity in August 2017 was the third strongest since 1980 (Fig. 2a) that preceded anomalously low ozone loss in spring. The latter was predicted by a regressive relationship (Fig. 2b) and indeed was observed in spring 2017 (Fig. 2b,c).

As August is the closest winter month to the ozone hole season September-November, wave activity in August can be critical for the polar vortex evolution in spring, considering also that planetary wave activity during the winter (spring) months is a significant preconditioning (influencing) factor for the ozone hole (Shindell et al. 1997; Allen et al. 2003), particularly in 2017 (Klekociuk et al. 2019). Antarctic ozone depletion starts typically in August (Lee et al. 2001; Solomon et al. 2005), and the wave intensification effects in the polar vortex (weakening of the zonal wind, warming of polar stratospheric air with decrease of the polar stratospheric cloud volume) leave an imprint on further state of the Antarctic stratosphere and resulted ozone loss. This has been confirmed statistically by a high correlation (up to $r=0.8$ ) between the QSWA in August and SeptemberNovember total ozone over Antarctica (Kravchenko et al. 2012). This is also in general consistent with that of Salby et al. (2012), who have shown that anomalous upward wave flux during late austral winter closely tracks anomalous springtime ozone.

As seen from the monthly means for August 2017, increased QSWA led to the appearance of the zonally asymmetric anomaly with high TOC level $\sim 360$ DU in the Australian sector (Fig. 1a). This anomaly contrasts with the quite symmetrical zonal TOC distribution with the mid-latitude maximum of $\sim 300$ DU in August 2015 (Fig. 1b), when low wave activity and strong polar vortex were observed (Tully et al. 2019). Differences between the 2 years (August 2017 minus August 2015) show negative zonal wind anomaly (of about $-12 \mathrm{~m} / \mathrm{s}$ ) in U50 and a positive temperature anomaly $\left(\sim 15^{\circ} \mathrm{C}\right)$ in $\mathrm{T} 50$ (Fig. $1 c, d$ respectively) in the same region of the zonal TOC anomaly.

Although located at the middle and sub-Antarctic latitudes, these anomalies are important for the polar vortex and ozone hole dynamics. First of all, they are associated with quasistationary stratospheric anticyclone in Australian sector of the SH stratosphere (Fig. 5) known as 'Australian High' (Harvey et al. 2002). In the SH stratosphere, anticyclones appear most often near South America, Africa and poleward of Australia (Harvey et al. 2002) and form prevailing wave 1 and wave 2 patterns in the Antarctic stratosphere (Figs 1 and 5). The Australian anticyclone is the manifestation of the QSW1 dominance, and it causes the polar vortex displacement towards the Atlantic sector, influences the lifetime of the polar vortex and ozone hole and alters the extent of springtime ozone loss (Harvey et al. 2002) and, as it intensifies, ozone hole split and its rapid disappearance are possible (Allen et al. 2003).

Polar vortex and stratospheric anticyclones tend to be descended through the stratosphere during winter and spring and at the same time anticyclogenesis tends to be increased as the vortex weakens (Harvey et al. 2002). Hence, anticyclone intensification in the middle stratosphere in August (upper panel in Fig. 5) can potentially affect the polar vortex and ozone hole in the lower stratosphere during September-November. Descent of air-temperature anomalies between July and November 2017 from Aura/MLS data seems to display this tendency between the upper and lower polar stratosphere (Klekociuk et al. 2019, their figure 3). Therefore, this tendency may indicate a contribution of the intense Australian anticyclone and related largeamplitude QSW in August to preconditioning of the ozone hole in spring (Fig. 2).

Large-amplitude QSW in the ozone field in August 2017 (Fig. 1a) and associated zonal wind weakening and air warming (Fig. 1c, d) appear due to tropospheric wave forcing (Fig. 5). Weaker zonal wind means that larger amplitude QSWs in August are able to more easily penetrate to the Antarctic stratosphere because of the Charney-Drazin theorem for wave propagation being more easily satisfied under conditions of weakened zonal winds (Charney and Drazin 1961). This provides additional ability for the late-winter QSW to influence the stratospheric dynamics in spring by growing wave activity. Note that this QSW effect is supported by the seasonal increase of the wave activity in the $\mathrm{SH}$ atmosphere with maximum in October (Randel 1988; Hardiman et al. 2010).

At the same time, we note that 1994, which is highlighted in Fig. $2 a$ (dashed curve) as a year having relatively large QSWA, did not have an anomalously small OHA (Fig. 2c). On the other 
hand, decreased OHA in 2012 (Fig. 2c) was not associated with an equally large QSWA in August 2012 (pink curve in Fig. 2a). So the large QSWA in the polar cap in August is not necessarily an exclusive indication of a small ozone hole in SeptemberNovember. This also follows from a high but not extreme correlation 'QSWA vs OHA' $(r=0.66$, Fig. $2 b)$. For the 38 ozone holes characterised from 1979, the ozone hole 2017 was ranked 29th using the 15-day average OHA and 26th using the total ozone mass deficit (Klekociuk et al. 2019). By our estimate from the mean OHA in September-November, the ozone hole 2017 was the 4th smallest among the anomalously small holes since 1988 (Fig. 2c), in general agreement with the QSWAs in August 2017 (Fig. 2a,b). Uncertainty in our attempt to predict the maximum area of the 2017 ozone hole (Fig. 2b, c) is not only associated with the particular regression model employed (Fig. 2b), but also with other analysis factors such as the method used to detrend the annual data, and the choice of a particular latitude circle $\left(70^{\circ} \mathrm{S}\right)$ and pressure level $(50 \mathrm{hPa})$. Nevertheless, our approach, which is based on a simple analysis technique and limited data sets, provides a predictive means of identifying cases when the area of the ozone hole is likely to be strongly influenced by dynamical activity.

We have identified the pathway of small-scale filament of tropical air (Fig. $4 a-c$ ) as lying between the polar vortex and stratospheric anticyclone near $0^{\circ} \mathrm{E}$ (long arrow on upper right plot in Fig. 5). There is much evidence that the stratospheric air transport and mixing in the polar regions are largely determined by an interaction between the vortex structures of cyclonic and anticyclonic types (Harvey et al. 2002). As noted earlier, tongues of tropical air can stretch and wrap the Antarctic polar vortex (Waugh 1993). Smaller regions of ozone-depleted air from the polar vortex have been noted to move around the Australian anticyclone (Allen et al. 2003) and be dispersed at lower latitudes. From case studies in the northern hemisphere, tropical air streamers can extend from the Eastern Pacific polewards and eastwards between the mobile anticyclone and the elongated Arctic vortex (Harvey et al. 2002).

Our results in Figs 4 and 5 demonstrate that the intrusion of the tropical air into the $\mathrm{SH}$ middle latitudes can occur between the adjacent edges of the polar cyclone and mid-latitude anticyclone, where a joint eastward circulation takes place. This is the region of intense planetary wave breaking (PWB), and PWB is efficient at irreversibly mixing air of different origins (Harvey et al. 2002). The growth of anticyclones promotes PWB which erodes the polar vortex, weakens it and decreases its area (Harvey et al. 2002). The equatorward flow at the eastern flank of the anticyclones allows thin filaments of air from the edge of the vortex to be removed through the advective action (Pierce and Fairlie 1993). A large part of these processes is associated with steady zonal asymmetry in the Antarctic stratosphere due to QSWs. The QSW1-induced wave breaking at the edge of the Antarctic polar vortex has been demonstrated by Moustaoui et al. (2013).

So, the evolution of stratospheric anticyclones in August 2017 influenced both the small-scale intrusion of tropical air and the large-scale vortex dynamics. The latter is associated with large-amplitude QSW and includes effects in the vortex off-pole displacement, seasonal tendency of the vortex descent and weakening and vortex edge erosion due to PWB. Although planetary waves destabilised the Antarctic polar vortex during winter and spring 2017 (Klekociuk et al. 2019), the late-winter wave impact in preconditioning the ozone hole is statistically significant on decadal time scale (Salby et al. 2012; Kravchenko et al. 2012) and, by our results, it was an important factor of decreased severity of the ozone hole 2017.

\section{Conclusions}

From analysis of wave activity in the extratropical SH in August 2017, it has been shown that the large-amplitude QSWs significantly contributed to anomalous decrease of the OHA in spring. The maximum OHA predicted for spring (September-November) 2017 based on linear regression with the QSWA in August was close to the observed value. Improved skill (lower mean squared error) in the prediction was provided by least-squares linear regression compared with reduced major axis regression.

Our results show that wave activity in August 2017 promoted the formation of the stratospheric anticyclones which disturbed the polar vortex and slowed down the development of the ozone hole. Large-amplitude QSWs in August 2017 associated mainly with the Australian stratospheric anticyclone contributed to the significant decrease of the OHA in spring in at least three ways. First, the Australian anticyclone was involved in the appearance of a large-amplitude QSW1 pattern in August that contributed to the weakening and off-pole displacement of the polar vortex. Weakened zonal winds were favourable for the growth of wave activity in the stratosphere, which became an important preconditioning factor prior to the formation of the ozone hole in spring.

Second, climatological descent of the anomalies between the upper and lower stratosphere during winter and spring implies the progressive penetration of those anomalies that were amplified in the middle stratosphere in late winter into the lower stratosphere in spring. The stratospheric anticyclones appear to have played a role in assisting with the amplification and downward progression of the anomalies.

Third, the growth of stratospheric anticyclones promoted PWB at the edge of the polar vortex that eroded the vortex and decreased its area. The stratospheric anticyclones of waves 1 and 2 in August 2017 were associated with tropospheric wave trains that propagated over the Atlantic-Indian and Pacific-Atlantic basins respectively. This suggests a dependence of the latewinter preconditions for the ozone hole not only on the wave activity itself, but also on large-scale wave structures in the troposphere. The causes of the changing wave patterns in August 2017 are potentially related to both the source region locations at the surface and the conditions for vertical propagation of the wave disturbances and need further study.

The tropical air filament extending from the South America eastwards and polewards into the SH stratosphere in August 2017 has been identified as having propagated between the edges of the polar vortex and the stratospheric anticyclone located near the Greenwich meridian. A filament in the ozone field contributed to the total ozone anomaly in the wave 2 pattern. The pathway taken by the filament is typical for those described in the earlier studies as fixed geographically in the same region. This confirms the role of climatological quasi-stationary components in the SH stratospheric circulation in weakening the ozone hole. 
The specific factors that lead to the anomalous wave activity require further study. Although we have identified the stratospheric anticyclones and tropospheric wave trains as playing an important role, specific climate modes may have been contributing factors. Specifically, as discussed in Klekociuk et al. (2019), the phase change that took place in the quasi-biennial oscillation over the winter of 2017 was favourable for poleward focusing of planetary wave activity. Additionally, the transition that occurred during winter from a strongly positive state of the tropospheric Southern Annular Mode to a generally neutral state indicated a weakening of zonal symmetry and strength of the tropospheric flow around Antarctica which would have aided disturbance to the high-latitude atmosphere.

\section{Acknowledgements}

Authors thank the two anonymous reviewers for their careful reading of the manuscript and helpful comments and suggestions. NCEP-NCAR reanalysis data were provided by the NOAA/OAR/ESRL Physical Sciences Division, Boulder, CO, USA, from their website at http://www.esrl.noaa. gov/psd/, accessed 30 April 2020. The ozone hole area was obtained from the Ozone Hole Watch website at https://ozonewatch.gsfc.nasa.gov/meteorology/SH.html, accessed 30 April 2020. The OMI total ozone fields have been obtained from the ESA TEMIS website at http://www.temis.nl/protocols/ O3global.html, accessed 30 April 2020. The stratospheric layer ozone column images are based on the Aura/MLS ozone data at https://mls.jpl.nasa. gov/, accessed 30 April 2020, and were acquired as part of the NASA's Earth-Sun System Division and archived and distributed by the Goddard Earth Sciences (GES), Data and Information Services Center (DISC) and Distributed Active Archive Center (DAAC). The SH stratospheric air trajectories from GFS/NCEP/US National Weather Service at https://earth. nullschool.net/, accessed 30 April 2020, are used. This work was supported by Taras Shevchenko National University of Kyiv, project 19BF051-08, and Australian Antarctic Science project 4293. This research did not receive any specific funding.

\section{References}

Agosta, E. A., and Canziani, P. O. (2011). Austral spring stratospheric and tropospheric circulation interannual variability. J. Clim. 24, 2629-2647. doi:10.1175/2010JCLI3418.1

Allen, D. R., Bevilacqua, R. M., Nedoluha, G. E., Randall, C. E., and Manney, G. L. (2003). Unusual stratospheric transport and mixing during the 2002 Antarctic winter. Geophys. Res. Lett. 30, 1599. doi:10. 1029/2003GL017117

Charney, J. G., and Drazin, P. G. (1961). Propagation of planetary-scale disturbances from the lower into the upper atmosphere. J. Geophys. Res. 66, 83-109. doi:10.1029/JZ066I001P00083

Grassi, B., Redaelli, G., and Visconti, G. (2008). Tropical SST preconditioning of the SH polar vortex during winter 2002. J. Clim. 21, 52955303. doi:10.1175/2008JCLI2136.1

Grytsai, A. V., Evtushevsky, O. M., and Milinevsky, G. P. (2008). Anomalous quasi-stationary planetary waves over the Antarctic region in 1988 and 2002. Ann. Geophys. 26, 1101-1108. doi:10.5194/ANGEO-26-1101-2008

Hardiman, S. C., Butchart, N., Osprey, S. M., Gray, L. J., Bushell, A. C., and Hinton, T. J. (2010). The climatology of the middle atmosphere in a vertically extended version of the Met Office's climate model. Part I: Mean state. J. Atmos. Sci. 67, 1509-1525. doi:10.1175/2009JAS3337.1

Harvey, V. L., Pierce, R. B., and Hitchman, M. H. (2002). A climatology of stratospheric polar vortices and anticyclones. J. Geophys. Res. 107(D20), 4442. doi:10.1029/2001JD001471

Huck, P. E., McDonald, A. J., Bodeker, G. E., and Struthers, H. (2005). Interannual variability in Antarctic ozone depletion controlled by planetary waves and polar temperature. Geophys. Res. Lett. 32, L13819. doi:10.1029/2005GL022943

Klekociuk, A. R., Tully, M. B., Krummel, P. B., Evtushevsky, O., Kravchenko, V., Henderson, S. I., Alexander, S. P., Querel, R. R., Nichol, S., Smale, D., Milinevsky, G. P., Grytsai, A., Fraser, P. J., Xiangdong, Z., Gies, H. P., Schofield, R., and Shanklin, J. D. (2019). The Antarctic ozone hole during 2017. J. South. Hemisph. Earth Syst. Sci. 69, 29-51. doi:10.1071/ES19019

Kodera, K., and Yamazaki, K. (1989). A possible influence of sea surface temperature variation on the recent development of ozone hole J. Meteorol. Soc. Jpn. 67, 465-472. doi:10.2151/JMSJ1965.67.3_465

Kravchenko, V. O., Evtushevsky, O. M., Grytsai, A. V., Klekociuk, A. R., Milinevsky, G. P., and Grytsai, Z. I. (2012). Quasi-stationary planetary waves in late winter Antarctic stratosphere temperature as a possible indicator of spring total ozone. Atmos. Chem. Phys. 12, 2865-2879. doi:10.5194/ACP-12-2865-2012

Lee, A. M., Roscoe, H. K., Jones, A. E., Haynes, P. H., Shuckburgh, E. F., Morrey, M. W., and Pumphrey, H. C. (2001). The impact of the mixing properties within the Antarctic stratospheric vortex on the ozone loss in spring. J. Geophys. Res. 106, 3203-3211. doi:10.1029/ 2000JD900398

Moustaoui, M., Teitelbaum, H., and Mahalov, A. (2013). Observation and simulation of wave breaking in the southern hemispheric stratosphere during VORCORE. Ann. Geophys. 31, 675-687. doi:10.5194/ANGEO31-675-2013

Nishii, K., and Nakamura, H. (2004). Tropospheric influence on the diminished Antarctic ozone hole in September 2002. Geophys. Res. Lett. 31, L16103. doi:10.1029/2004GL019532

Peters, D., Vargin, P., and Körnich, H. (2007). A study of the zonally asymmetric tropospheric forcing of the austral vortex splitting during September 2002. Tellus 59A, 384-394. doi:10.1111/J.1600-0870.2007. 00228.X

Pierce, R. B., and Fairlie, T. D. A. (1993). Chaotic advection in the stratosphere: Implications for the dispersal of chemically perturbed air from the polar vortex. J. Geophys. Res. 98, 18589-18595. doi:10.1029/ 93JD01619

Randel, W. J. (1988). The seasonal evolution of planetary waves in the southern hemisphere stratosphere and troposphere. Q. J. Roy Meteor. Soc. 114, 1385-1409. doi:10.1002/QJ.49711448403

Randel, W. J., Gille, J. C., Roche, A. E., Kumer, J. B., Mergenthaler, J. L., Waters, J. W., Fishbein, E. F., and Lahoz, W. A. (1993). Stratospheric transport from the tropics to middle latitudes by planetary-wave mixing. Nature 365, 533-535. doi:10.1038/365533A0

Salby, M. L., Titova, E. A., and Deschamps, L. (2012). Changes of the Antarctic ozone hole: controlling mechanisms, seasonal predictability, and evolution. J. Geophys. Res. 117(D10), D10111. doi:10.1029/ 2011JD016285

Shindell, D. T., Wong, S., and Rind, D. (1997). Interannual variability of the Antarctic ozone hole in a GCM. Part I: The influence of tropospheric wave variability. J. Atmos. Sci. 54, 2308-2319. doi:10.1175/15200469(1997)054<2308:IVOTAO > 2.0.CO;2

Solomon, S., Portmann, R. W., Sasaki, T., Hofmann, D. J., and Thompson, D. W. J. (2005). Four decades of ozonesonde measurements over Antarctica. J. Geophys. Res. 110, D21311. doi:10.1029/2005JD005917

Tully, M. B., Klekociuk, A. R., Krummel, P. B., Gies, H. P., Alexander, S. P., Fraser, P. J., Henderson, S. I., Schofield, R., Shanklin, J. D., and Stone, K. A. (2019). The Antarctic ozone hole during 2015 and 2016. J. South. Hemisph. Earth Syst. Sci. 69, 16-28. doi:10.1071/ES19021

Waugh, D. W. (1993). Subtropical stratospheric mixing linked to disturbances in the polar vortices. Nature 365, 535-537. doi:10.1038/365535A0

Wu, C., and Yu, J. Z. (2018). Evaluation of linear regression techniques for atmospheric applications: the importance of appropriate weighting. Atmos. Meas. Tech. 11, 1233-1250. doi:10.5194/AMT-11-1233-2018 